\title{
Teorias de texto e de discurso: inconciliáveis?
}

Sírio Possenti

\section{Resumo}

O trabalho parte da constatação de que não há, praticamente, debates ou polêmicas na academia brasileira, pelo menos na área de estudos da linguagem. Depois de expor a tese de Dascal sobre a relevância das controvérsias, concentra-se na distinção entre os estudos de texto e de discurso, que eventualmente são aproximados, pelo menos pela ocorrência de certos termos, especialmente "discurso". Apresenta as diferenças fundamentais em relação a determinadas questões (sujeito, leitura, multissemiose) e concentra-se nas diferentes concepções sobre um tema que os estudos de texto tornaram corrente no Brasil, a referenciação. A tese é que as soluções da análise do discurso e dos estudos de texto são incompatíveis e que temas como este deveriam ser explicitamente debatidos, como se se tratasse de "descobrir" efetivamente a melhor solução.

Palavras-chave: controvérsia, discurso, texto, referenciação 


\section{Introdução}

Preciso começar este texto com duas notas quase pessoais, e bem diferentes entre si. A primeira é que tenho um gosto pelas polêmicas (embora o cultive menos do que gostaria). Já disse a amigos que, se pudesse, viveria delas. Ou seja, gastaria de bom grado meu tempo debatendo dados, análises, argumentos. De certa forma, exercito esse meu gosto nas colunas que escrevo há uma dúzia de anos na imprensa, primeiro em um jornal do interior paulista (Jundiaí), depois em mídias eletrônicas. Mas essas polêmicas privilegiam "interlocutores" da própria mídia - jornalistas, colunistas, intelectuais diversos e políticos que decidem pronunciar-se sobre questões de língua. É "contra" eles que a maioria de minhas colunas é produzida. Se tomam conhecimento delas, fazem de conta que não as leram. Só uma ou duas vezes escrevi claramente sobre leituras de textos de minha autoria feitas na academia. Mas creio que posso dizer que quase tudo o que escrevi era motivado por esta espécie de sanha de debater com alguém.

A segunda nota é sobre a inexistência de debates na academia brasileira, de forma que tenho que alimentar meu gosto lendo o que ocorre em outros países. Há pouco tempo, escrevi um prefácio um pouco em desacordo com as regras do gênero (pelo menos entre nós). Estas, aparentemente, obrigam a elogiar e, quando se trata de coletâneas, a fazer um resumo de cada texto, como para ensinar a ler o livro. Fui mais ou menos execrado, pelo que sei. A consequência mais óbvia dessa quebra das regras, dessa pequena heresia (eu dizia que o livro era bom, mas indicava uma direção dissonante em relação a teses fundadoras do campo, e que cumpria esperar para ver se a tendência se afirmaria ou não) foi a diminuição de convites para bancas e outras participações similares em determinados espaços. Mas não houve uma resposta escrita, nem mesmo uma conversa direta.

Um dos corolários desse estado da questão é que as resenhas são sempre amigáveis, feitas por alguém do grupo. Acrescento imediatamente que considero as resenhas "de dentro" fundamentais, porque penso que é verdade que só assim estão dadas as condições para uma leitura adequada do texto resenhado (as teorias sobre a relevância da ideologia para o "progresso" do conhecimento explicam esse fato (ver Löwy 2003, especialmente o capítulo sobre o marxismo). Mas fazem falta as resenhas "de fora", as que explicitariam possíveis limites das obras, eventualmente, seus problemas ou defeitos, ou, mais amplamente, alternativas de análise.

\section{Um motor?}

Dascal (1994) defende que o "avanço" da ciência se deve às controvérsias. Constata o fracasso da epistemologia lógico-positivista, tanto em suas vertentes normativas (as que ditam com- 
portamentos aos cientistas - quer sejam indutivistas, quer sejam dedutivistas, quer estejam entre os que acreditam que devem testar duramente suas hipóteses ou mesmo ser persistentes diante do falseamento delas) quanto nas descritivas (que pretendem dizer como a ciência "avança" pela análise de sua história). Segundo ele, nenhuma dessas propostas tem espaço para a consideração do papel das controvérsias, que, a seu ver, são o verdadeiro motor da ciência.

Apresenta duas teses gerais sobre as controvérsias: (I) As controvérsias são indispensáveis para a formação, evolução e avaliação das teorias; (II) A pesquisa das controvérsias é indispensável para uma descrição adequada da história e da práxis das ciências.

Distingue, num terceiro passo, no interior do fato empírico "discurso polêmico", as discussões, as disputas e as controvérsias. Caracteriza as primeiras como polêmicas cujo tema é bem circunscrito. Os participantes da discussão tendem a reconhecer que o problema é um erro relativo a algum conceito ou procedimento. Discussões permitem soluções. Uma disputa envolve, além de problemas ou procedimentos, diferenças de atitudes, sentimentos ou preferências. Não há procedimentos mutuamente aceitos para decidi-las; ou seja, elas não têm soluções. As controvérsias estão em posição intermediária entre as duas anteriores. Podem começar com um problema específico, mas logo se expandem para outros e revelam divergências profundas. Envolvem preferências, mas não se reduzem a elas. A eventual resolução pode consistir no reconhecimento de que se acumularam mais argumentos ou dados em favor de uma posição do que de outra. Um dos efeitos é que ambas as posições podem resultar em parte modificadas.

As principais características das controvérsias são: a) não se confinam aos problemas iniciais; b) os contendores questionam os fundamentos da posição contrária, sejam factuais, sejam metodológicos, sejam conceituais; c) os contendores discutem os procedimentos hermenêuticos dos adversários; d) são abertas, ou seja, não se sabe onde vão desembocar; e) encerram-se sem "fechar" a questão; f) sua abertura não implica anarquia, ou seja, nelas não há vale-tudo (Dascal 1994, passim).

Minha experiência de análise de um debate ${ }^{1}$ deixou a seguinte impressão: que as posições dos contendores são mais facilmente modificáveis a partir dos dados. Mostrar outros dados e/ ou que os dados que sustentam uma posição foram mal coletados enfraquece posições ou leva contendores a admitir problemas em seus trabalhos mais comumente do que apresentar argumentos metafísicos ou ideológicos contrários.

Talvez valha a pena mencionar a posição de Maingueneau

1 Apelo para esta palavra para não tomar posição em relação ao enquadramento do caso na tipologia de Dascal...
(1984/2008) sobre as polêmicas. Ele analisa o embate entre duas formações discursivas (que depois chamaria de posicionamentos) religiosas no espaço do cristianismo devoto. Sua tese é que a polêmica é regida pela semântica de cada FD, de forma que os 
contendores não se "entendem" (a polêmica é regida pelo que ele chama de "interincompreensão regrada", que não implica nem desonestidade intelectual nem deficiências cognitivas, mas apenas decorre do fato de que cada contendor lê o outro a partir de sua semântica, do que deriva que nunca se "compreendem"). É o verdadeiro diálogo de surdos. Maingueneau compara a interincompreensão à incomensurabilidade que haveria entre paradigmas e ressalta uma diferença: no caso de teorias opostas, é possível que a controvérsia seja resolvida em favor de uma (pelos dados, eventualmente); no caso das polêmicas ideológicas, não há um juiz exterior e acima das duas posições que possa definir vitoriosos. Quando os há, os motivos são outros: um grupo desaparece, por exemplo, e o que a história pode fazer é explicar esse fato. É exatamente o caso dos jansenistas, um dos polos da polêmica que Maingueneau analisa.

\section{Um debate surdo}

Meu objetivo, neste trabalho, é apresentar bastante informalmente ${ }^{2}$ as questões teóricas (e algumas empíricas) centrais que dividem as teorias de texto e as de discurso. Meu argumento - nada novo - é que elas não são equivalentes, nem complementares, e que não são simplesmente duas maneiras de fazer a mesma coisa. Eventualmente, trata-se de explicações concorrentes para os mesmos fatos. Mas, em geral, mais do que isso, trata-se de teorias, ou de conjuntos de teorias, que funcionam paralelamente, sem intercâmbio e mesmo sem debate. Esta característica não deixa de ser curiosa, porque pode dar a entender que não há interesse em resolver de fato determinados problemas, mas apenas em que as duas comunidades discursivas sobrevivam, cada uma resolvendo a sua maneira os problemas que formula para si e nos seus termos. O "sonho" deste texto é que, por alguma razão, passe a haver um debate sobre as diferentes soluções para problemas semelhantes. Mas ele não resulta de nenhum traço de otimismo.

Nos estudos de texto e de discurso (esta terminologia vai aos poucos se fixando, em certos casos em detrimento dos termos

2 Por isso não trato de estudos específicos e, portanto, não há citação de nenhum trabalho. Se o fizesse, talvez criasse mais problemas do que imagino criar por ora.

3 Ponho a palavra entre aspas apenas porque, em geral, não há uma teoria em cada um dos lados, mas teorias mais ou menos próximas ou que partilham de elementos comuns; essas características constituem nitidamente dois pontos de vista distintos.
"Análise do Discurso" e "Linguística Textual" ou "do Texto"), há aspectos que se superpõem e para os quais as palavras "texto" e "discurso" podem ser - ou têm sido - eventualmente intercambiadas. Mas há questões para as quais é de relevância crucial distinguir entre as denominações, que não são duas por mero acaso, e também propor quadros teóricos claros de cada uma delas (eventualmente, mencionando suas diferenças). Às vezes, é absolutamente necessário explicitar (ou explicitar de novo) quais são os problemas concernidos, ou fundamentais, e quais são deixados de lado ou postos em segundo plano por cada uma das "teorias"3.

Antes de mais nada, creio que vale a pena fazer uma observação relativa ao que poderia parecer mera casualidade, ou 
simples questão de palavras, mas que, de fato, é bem mais do que isso: o termo "discurso" é frequentemente empregado em trabalhos de linguística textual e até mesmo nos de sociolinguística ou de análise da conversação em acepções que não se aproximam das que são consideradas relevantes pelos analistas de discurso (por mais que haja diferenças entre as diversas teorias que adotam ou adotaram esta denominação).

Este fato parece ser sintoma de um certo prestígio (a requerer explicação mais detalhada) do termo "discurso" e dos sentidos que lhe são associados, e que a palavra "texto" não evoca. Uma hipótese é que o termo "discurso" implica ou supõe um desejo de afastar-se do que soa como apenas "linguístico" e de aproximar-se do que soa como "social" ou "cultural" ou "psicológico". Ou mesmo "ideológico". As linguísticas de texto deixaram há bastante tempo de ser apenas "linguísticas" e se tornaram em boa medida fortemente marcadas pela psicologia cognitiva e mesmo pela atenção a outros problemas, originariamente não textuais em sentido estrito, como, por exemplo, a intertextualidade. Creio que foi esta expansão que fez com que "discurso" parecesse um termo não incompatível com textualidade. Penso que não deveria mesmo ser, mas por outras razões.

Talvez um espaço para uma compreensão mais adequada desse fenômeno, que, a meu ver, como disse, não é banal, porque indica opções diversas dos estudos da linguagem, sejam as abordagens dos gêneros (no sentido textual-discursivo, não no sentido de "sexual", é óbvio). A noção revitalizada por Bakhtin tinha, na obra do pensador russo, claríssimos ingredientes que "ultrapassavam" a questão da estrutura interna do texto. Dado decisivo, ou constitutivo, é seu pertencimento a uma esfera ou campo. Resta verificar em que medida esse "algo mais" está presente, ou, alternativamente, ocupa o primeiro ou pelo menos o segundo plano nas abordagens que atualmente se fazem da questão. Conforme se trate de uma ou de outra "escolha", ela indicará até que ponto se incluem de fato no próprio objeto de estudo as questões que são também, ou originariamente, "sociais" (adoto esta palavra aqui para referir o que, nas teorias "duras" de discurso, se designa com a expressão "exterioridade"), ou se elas são acrescidas ao núcleo duro de uma teoria como um elemento a mais a ser considerado e a ser explicado, então, por uma teoria específica de outro campo.

O exemplo mais claro desse emprego de "discurso" ocorre nos trabalhos de linguística de texto ou de análise da conversação que consideram central a problemática da referenciação, tal como definida em Mondada e Dubois, e implementada no Brasil principalmente por Marcuschi e Koch, nitidamente em oposição a uma real ou suposta postulação da relação direta entre as palavras e as coisas, vale dizer, a uma solução "linguística" ingênua - sem "enunciação", sem relação interacional ou dialógica etc. - para a questão. O adjetivo "discursivo" tem quase sempre, nesses traba- 
lhos, um sentido muito diferente do que tem a mesma palavra, por exemplo, em Foucault, em Pêcheux e em Maingueneau, e mesmo em Charaudeau.

O processo de referenciação é concebido pela LT como sociocognitivo, por um lado, mas, por outro, está ligado a processamentos individuais ou, no máximo, interacionais, admitindo-se que o sentido, ou as diversas alternativas de referenciação (nomeação, predicação...) possam ser negociadas, eventualmente durante o próprio processamento on-line da conversação. Como se vê, a ênfase recai sobre a cognição e/ou sobre as opções individuais.

Se a AD considerar os mesmos dados para análise, voltará seu olhar para o que ela considera fatos históricos: as diversas maneiras de referir-se a um "objeto" (do mundo ou do universo de discurso) serão "buscadas" no interdiscurso, na memória discursiva, e serão "selecionadas" pelo enunciador (e não produzidas por ele) segundo critérios da teoria, da formação discursiva ou do campo em que o discurso é produzido (ver os dois exemplos no final do texto).

\section{Diferenças}

Este trabalho, como foi dito acima, pretende comentar um conjunto de opções que diferenciam as teorias de texto e as de discurso, na medida em que elas oferecem explicações claramente distintas para determinados problemas. Essas teorias consideram cruciais explicações ou psicossociológicas ou históricas; consideram a memória ou em termos cognitivos ou em termos psicanalíticos e/ou históricos; consideram fundamental um corpus institucional (mais frequentemente escrito) ou um corpus sem a consideração dos laços institucionais (independentemente de ser falado ou escrito), tratam diferentemente questões como a legibilidade dos textos, vale dizer, o processo de leitura e a figura do leitor etc.

Frequentemente, trabalhos nesses campos apresentam traços marcantes de "ecletismo", nem sempre, é verdade, com o mesmo grau ou com a mesma sem cerimônia. As diferenças básicas entre eles são de três tipos: a) há trabalhos que adotam ou dizem adotar perspectivas associadas a diversos autores, ora mais, ora menos

4 A afirmação de Foucault de que uma obra é um nó numa rede pode ser aproximada, mas certamente não é equivalente nem nasce do mesmo quadro em que nascem as teses de Bakhtin sobre o dialogismo ou as de Pêcheux ou de Maingueneau sobre interdiscurso. Certamente, porém, estão mais próximos entre si do que estão as de Chomsky ou mesmo de Halliday e Hasan, ou de Van Dijk. compatíveis. Bons exemplos são Pêcheux, Foucault e Bakhtin, que, provavelmente, formam um "grupo" (seu ponto de partida é o social ou o histórico, não o individual ou o biológico) que pode ser claramente oposto a outro (que privilegie o individual e o biológico), sem que, no entanto, eles se filiem exatamente à mesma ${ }^{4}$; b) há trabalhos que adotam perspectivas que talvez possam ser compatibilizadas, mas que exigem este trabalho de compatibilização, sempre por fazer (são exemplos os diversos - na verdade, numerosos - trabalhos que incorporam teses da pósmodernidade às problemáticas formuladas pela $\mathrm{AD}$, não sendo claro que, por exemplo, uma categoria como "o sujeito da pós 
modernidade" seja compatível com a categoria correspondente em Foucault, em Pêcheux, em Bakhtin ou em Maingueneau); c) há trabalhos que "misturam" claramente, e, aparentemente, como se pudessem ser apenas "somados", procedimentos, hipóteses e "axiomas" oriundos de teorias bastante diferentes entre si em seus fundamentos mais característicos (por exemplo, as teses de Marcuschi, de Bakhtin e de Maingueneau sobre gênero).

Não pretendo concluir que há teorias melhores do que outras, nem que, se as houvesse, deveria haver alguma pressão "ética" para que as menos boas fossem abandonadas em favor das melhores (ou que deixassem de receber financiamentos). Nem por isso, no entanto, deixarei de tomar posição em relação a determinadas análises, emitindo, eventualmente, juízos de valor.

A diferença fundamental entre a LT e a AD está clara em duas ou três questões filosóficas. Uma diz respeito ao sujeito: para a LT, explicita ou implicitamente, o sujeito (falante, locutor, leitor) é de tipo cartesiano: é uma unidade de consciência e de saber. Locutores e leitores são concebidos como (ou muito aproximados de) falantes e leitores empíricos. Não há na LT categorias específicas para referir-se aos indivíduos e às "personagens" textuais ou discursivas. Esta caracterização sumária (talvez simplificada) pode ser mais claramente atestada nos trabalhos de análise da conversação, cujas diferenças filosóficas de fundo em relação à LT praticamente inexistem. A consideração da memória e da atividade inferencial são outros elementos que confirmam essa concepção, frequentemente não explicitada no próprio interior da LT, cuja "psicologia" deve ser visitada nos textos próprios desta outra disciplina. O locutor está na fonte do texto e o leitor na origem da leitura (ele é mesmo "o que lê").

Para a AD (talvez essa seja sua tese mais conhecida), o sujeito é concebido como efeito, marcado pelo inconsciente e pela ideologia; é "dividido / disperso", o que significa que, no que se refere a seu saber, à memória, à manipulação dos textos, às atividades de

5 Para Bakhtin e Maingueneau, apesar das diferenças, é o pertencimento a um campo ou a uma esfera o ponto de partida para definir um gênero, e não seu formato textual. A tese de Marcuschi mais conhecida sobre a questão é sua postulação de um continuum entre fala e escrita (isto é, de uma não ruptura entre as duas modalidades), ou seja, sua ênfase recai sobre a "composição" do texto genérico.

6 É evidente que tais expressões não têm sentido óbvio; mas são indicadoras de uma incompatibilidade básica. interpretação etc., é marcadamente concebido como "efeito". Por exemplo, a tese da AD é que sujeitos ocupam posições "previstas" pelos discursos (pelas práticas discursivas), a cujas regras estão submetidos - eventualmente mais em alguns campos que em outros. A diferença pode ser formulada nos seguintes termos: para a LT, o sujeito é origem; para a $\mathrm{AD}$, ele é efeito 6 .

Outra diferença fundamental: a LT considera qualquer texto como texto, ou seja, como categoria primeira, sem questionar se sua natureza, ou determinado traço que o caracteriza, é condicionada de alguma forma pelo campo ou esfera em que este texto é "gerado" e circula. Trate-se de questões de coerência ou de referenciação, os fatos são analisados independentemente de explicitar se tal traço é ou não característico de certos tipos de textos (por exemplo, dos poéticos ou dos científicos). Para a AD, a consideração do campo é fundamental: para as análises discursi- 
vas, o ponto de partida é a inscrição institucional do texto (tanto quanto do enunciador). Um poema é "coerente" por razões que não valem necessariamente para um paper ou para um chiste. As discussões sobre gêneros textuais levadas a cabo no interior da LT poderiam modificar esta divisão, mas as análises não têm sido afetadas crucialmente por este fato.

Estas duas diferenças explicam a tendência da LT a aceitar determinadas formas de negociação ou de produção de sentido (de base interacional), o que é basicamente inaceitável para a $\mathrm{AD}$, que concebe o sentido como derivado de unidades como as formações discursivas ou os campos: como "negociar" sentidos jurídicos ou científicos a não ser com outros discursos jurídicos ou científicos? Outra questão, paralela, e talvez ainda mais crucial: posicionamentos diferentes negociam sentidos? Basta ver debates políticos, religiosos, jurídicos e outros, mesmo alguns científicos, para verificar que tal negociação é rara. Os enunciadores só negociam em relação a questões de pouco relevo: cerveja mais ou menos gelada, mais ou menos tempero na comida. Mas um vegetariano não "negocia" com um carnívoro, nem um abstêmio com um consumidor de álcool. Muito menos um ateu com um religioso, um machista ou um racista com defensores de direitos iguais.

Estas diferenças ao mesmo tempo decorrem de e implicam outra: a LT trata do leitor empírico: uma leitura será bem ou mal sucedida, no que for relevante, em decorrência de certas competências do leitor (na verdade, dos leitores). Tanto é assim que experimentos para medir sucesso ou insucesso de leituras fazem todo o sentido para a LT. Mas, certamente, não fariam sentido para a $\mathrm{AD}$, porque, para a $\mathrm{AD}$ (na verdade, para todas as teorias para as quais a questão da enunciação é fundamental), o leitor é uma personagem discursiva (bem como o locutor / enunciador / sujeito / autor).

Ainda como decorrência dessas diferenças, ainda outra é fundamental. Diz respeito à concepção de memória. Para a LT, a memória é de certa forma pessoal, enquanto para a AD é um conceito marcadamente institucional e histórico. Para a LT, memória se aproxima de lembrança mais do que de arquivos, para usar definienda nada evidentes. Uma incursão mais detalhada no campo mostrará que esta diferença se manifesta claramente também quando se trata das memórias de longo ou de curto prazo: memória de trabalho é uma expressão que pode ser de extrema relevância (uma questão empírica a não ser desprezada) para teorias de texto, especialmente de leitura, mas certamente é um corpo estranho nas teorias de discurso. Evidentemente, memórias de fundamento neurológico só fazem sentido para falantes empíricos, não para enunciadores; para escritores, mas não para autores. Diga-se que uma questão que pode ser incômoda para a AD é em que medida ela faz sentido para sujeitos... 
Uma das diferenças mais cruciais entre as duas abordagens, certamente, é o tratamento da intertextualidade. Para a LT, coerentemente, o prefixo "inter" só se aplica à intertextualidade, e se aplica a textos independentemente de outros efeitos ou condições. Para a AD, a distinção entre intertextualidade e interdiscursividade é decisiva. Mas não se trata, para a $\mathrm{AD}$, apenas de distinguir dois fenômenos onde, para a LT há só um. Trata-se de subordinar a intertextualidade à interdiscursividade: ou seja, para a $\mathrm{AD}$, a forma de citação do Outro texto no interior do Um se define por suas afinidades ideológicas (ou teóricas) ou por sua incompatibilidade. Para a $\mathrm{AD}$, haver mais de um locutor não é suficiente para que haja polifonia. Para tanto, é necessário que haja mais de uma "voz social", ou seja, mais de um posicionamento ou mais de uma ideologia expressos no texto. Para a AD, o interdiscurso comanda o intradiscurso, de que as "vozes" e as relações (anafóricas e outras) de retomada são exemplos.

Mais do que isso: para a $\mathrm{AD}$, sempre há interdiscursividade, mesmo que um texto não mencione outro ("a Terra é redonda" opõe-se a "a Terra é plana", mesmo que a menção a esta outra concepção astronômica não ocorra neste texto - o que é um bom exemplo da diferença de concepção do funcionamento da memória, aliás).

Que a $\mathrm{AD}$ e a LT operem tipicamente sobre corpora diferentes não é mera casualidade. Um dos traços característicos da LT é fundir-se, de certa forma, à análise da conversação (textos sobre referenciação, por exemplo, incluem quase sempre dados oriundos de "língua falada"). Por outro lado, um dos traços mais característicos da AD é operar tipicamente com textos institucionais. Ambos os casos têm o efeito de poderem, intuitivamente, pelo menos, dar conteúdo empírico mais aos posicionamentos ou mais aos falantes, mais ao arquivo ou à lembrança, mais à relação institucional ou à interação. Os casos extremos são, assim, exemplares: é mais intuitivo que um sentido não possa ser negociado se ele é característico de uma teoria; e que possa sê-lo se ele parece uma questão de preferência ou gosto (mesmo que não seja).

Há outra diferença relacionada aparentemente ao corpus: as teorias associadas a teses filosóficas típicas da LT tratam dos fenômenos da multissemiose em termos de multimodalidade, enquanto as teorias de AD tratam dos fenômenos de multimodalidade em termos de multissemiose. O que significa que as teorias de LT (ou que lhe são próximas) privilegiam - sem contar que fazem de conta que se trata de um fenômeno recente, quase associado à informática - a diversidade dos meios para produzir sentidos (textos são multimodais e sua leitura exige competências específicas). As teorias de $\mathrm{AD}$, por sua vez, e ao contrário, privilegiam a unidade de sentido; isto é, para elas é mais relevante o fato de que os diversos meios se orientam para uma (só) significação (ou para significações retomadas, aludidas etc., típicas da 
interdiscursividade). Os casos mais evidentes são aqueles em que uma legenda diz a mesma coisa que uma fotografia. Casos menos óbvios são aqueles em que uma "imagem" se associa claramente a uma ideologia, a uma formação discursiva, a uma doutrina (de que a publicidade, política ou comercial, fornece excelentes ilustrações).

\section{Dois exemplos}

Em uma viagem ao México, há algum tempo, li noticiário sobre um desempenho ruim da seleção brasileira de futebol em um torneio que acabara de ocorrer. No meio do texto, os atletas brasileiros eram referidos ora como "los amazônicos", ora como "los cariocas". Perguntei a colegas de lá se nos viam como "amazônicos", e a resposta era "sí", em tom que implicava obviedade. Expressei minha estranheza. Então me perguntaram se nós também não os referimos como "astecas", e eu disse que sim, mas que achava que eles são astecas. A resposta foi que eles acham que somos amazônicos...

Creio que se trata de um bom exemplo para mostrar que não há "mapeamento" na relação entre as palavras e as coisas (mas quem, mesmo, defende que haja?). Mas, por outro lado, o exemplo mostra que não se trata de uma questão cognitiva ou interacional. Em nada adiantou dizer-lhes que a Amazônia é apenas uma das regiões do Brasil. Não se tratava de geografia, como ficou evidente. Nem de conhecimento ou de ausência de conhecimento prévio. Trata-se de uma questão ideológica, ou de estereótipos, de certa forma "imposta" aos mexicanos (a meio mundo, na verdade).

Em junho de 2009, ocorreu uma ocupação do campus da USP pela polícia militar. Durante o evento, um manifesto assinado por um conjunto (não por todos, ainda bem!) de diretores de unidades incluía o seguinte parágrafo:

Conclamamos toda a comunidade universitária ao entendimento em torno do respeito ao direito de greve e da livre expressão de ideias, refutando qualquer tipo de violência, seja por grevistas ou por policiais. Ao mesmo tempo, enfatizamos que, nos termos da lei, as manifestações e atos de persuasão utilizados pelos grevistas devem preservar o acesso ao trabalho, sem causar ameaça ou dano às pessoas ou ao patrimônio público, como os que geraram, em primeira instância, a necessidade das ações judiciais de reintegração de posse e a subsequente presença da polícia no campus para seu cumprimento.

Segundo a AD, a ocorrência do sintagma "a necessidade" decorre de uma certa formação discursiva (ou posicionamento), de sua memória, de seus pré-construídos: é para a certa posição ideológica que defendeu (a ainda defende!) a intervenção policial na universidade que as ações judiciais e a presença da polícia no

7 Nem vale a pena comentar que me pediam que sambasse! campus podem ser postas em termos de necessidade. Tanto é assim que cerca de uma dezena de diretores não assinou a nota. Ora, 
a discordância não diz respeito a questões de textualização, mas a posicionamentos. Não se trata de uma categorização, mas de um pré-construído. Para os que assinam a nota, "a necessidade" é uma expressão óbvia, que deriva da formulação prévia - real ou hipotética - "ações judiciais de reintegração são necessárias". Modalidade? Sim. Mas por que a necessidade em vez da impossibilidade?

\title{
Conclusão
}

Que explicações de natureza cognitiva sejam postuladas no lugar de outras, históricas ou psicanalíticas (determinadas associações), é legítimo. Tão legítimo quanto a decisão inversa. Pode ser que se trate de preferências às quais não faltam ingredientes de ordem metafísica (o que é mesmo um ser humano? como sua mente funciona? como ele aprende? o que se deve saber para falar de certa maneira? o saber é consciente? o que é uma escolha entre alternativas? ela existe?), portanto, de certa forma indecidíveis.

A questão que poderia ser proposta é se existem casos em que uma explicação histórica ou institucional é efetivamente mais correta do que uma psicológica e individual (minha posição é que sim). Nestes casos, ainda haveria lugar para escolhas?

O que significa o fato de a academia não realizar debates abertos sobre temas como os aqui rapidamente mencionados? Significa que não se trata de erros contra verdades, mas de opções, e que todas têm o mesmo valor? Há teorias a serem compatibilizadas, como se sua relação fosse de inclusão, de algum tipo de inclusão, e não de exclusão? Por exemplo, para mencionar dados que a $\mathrm{AD}$ não considera tipicamente: uma memória "neurológica" pode incluir uma "psicanalítica" ou ser incluída por ela, na medida em que lesões produzem efeitos que não podem ser desconsiderados em sua natureza biológica?

Certamente, ainda há caminhos a serem trilhados. O que é preocupante, a meu ver, é que não há debate no horizonte. Sem ele, cada uma das duas vertentes continuará seguindo seu caminho, e os adeptos de cada uma delas continuarão falando basicamente para seus pares, todos já convencidos de que estão certos.

Se um dia sairmos deste estado, haverá disputas, controvérsias ou discussões? Ou estaremos imersos em uma polêmica, no sentido que Maingueneau dá à expressão? Talvez nunca venhamos a saber...

\author{
Abstract \\ This work believes that there is hardly any debates \\ or controversy in the Brazilian academy, at least \\ in the area of language studies. After reflecting \\ about the theory of Dascal, which discusses the \\ relevance of the controversies, the distinction \\ between studies of text and studies of discourse
}


is analyzed, since the term "discourse" is often related to both of them. It is presented the fundamental differences on certain issues (subject, reading, multisemiosis) and it is emphasized the different conceptions about a current subject in Brazil: the reference. The thesis is that the solutions from discourse analysis and from the study of text are incompatible and that issues like this should be explicitly discussed, as if to "discover" the best solution.

Keywords: controversy, discourse, text, reference.

\section{REFERÊNCIAS}

DASCAL, M. Epistemologia, controvérsias e pragmática. In: Revista da SBHC, 12. pp. 73-98. 1994.

LÖWY, M. As aventuras de Karl Marx contra o Barão de Münchhausen - marxismo e positivismo na sociedade do conhecimento. São Paulo: Cortez Editora. 2003.

MAINGUEANEAU, D. Gênese dos discursos. São Paulo: Parábola. 1984/2008. 